QR Codes and Electronic Books

by Helen Greenwood

\title{
QR Codes and \\ Electronic Books
}

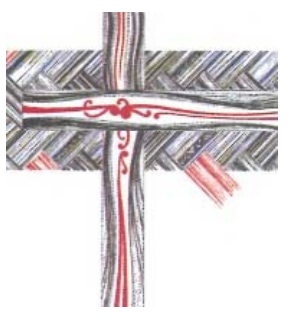

\author{
Helen Greenwood
}

John Kinder Theological Library

Auckland, New Zealand

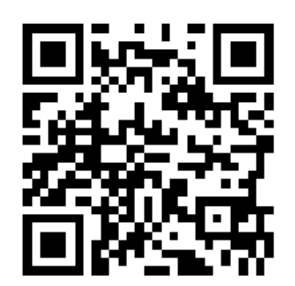




\section{Problem}

\section{Trying to increase the visibility and therefore the use of electronic books}

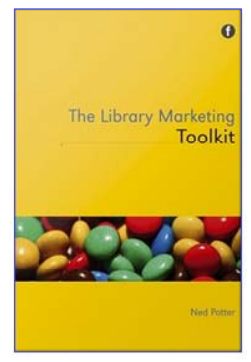

Potter, Ned. Library marketing toolkit. London : Facet Publishing, 2012. ISBN 9781856048064

QR Codes are a great way to integrate paper and electronic collections. My colleague Susan Clayton suggests putting QR Codes on the physical shelves above the books - these then link to the e-Book equivalent of the physical stock that sits on these shelves. If the books aren't there, the user sees a sign saying 'Scan this QR Code to be taken to the e-book of [insert title here]' - much quicker than looking it up in the catalogue. 


\section{What is a QR code}

QR stands for 'Quick Response'. A QR code is essentially like a barcode that you might find on a packet of food, except that it can be scanned by a mobile device - when you scan a QR Code it takes you to a specific website online.

Potter, p. 124

\section{This QR code takes you to the Library Marketing Toolkit website}

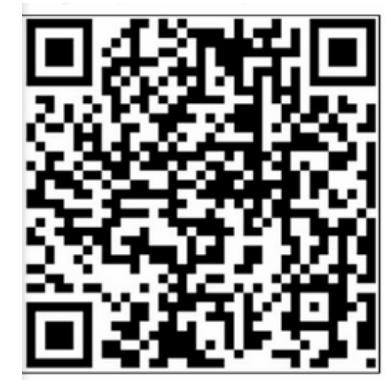




\section{Creating a QR code}

There are many free websites that will create QR codes

These are the two I have used

www.qrcode.kaywa.com

www.qrstuff.com

Copy and paste the URL into the QR code generator to create code

Note to self: make sure you use the $Q R$ code from the 856 of your catalogue record to ensure that you get to your library's authentication page 


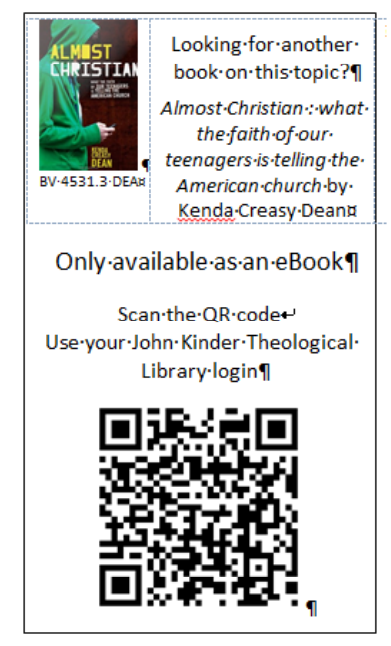

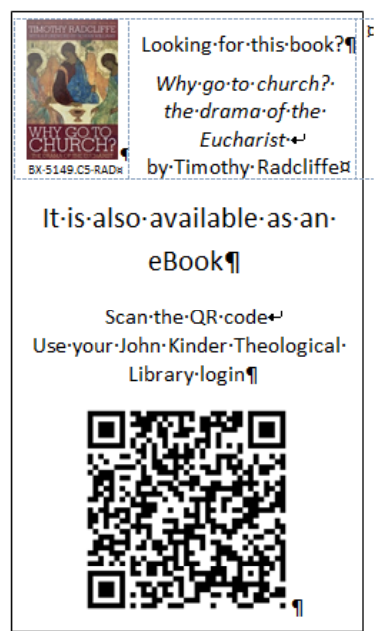

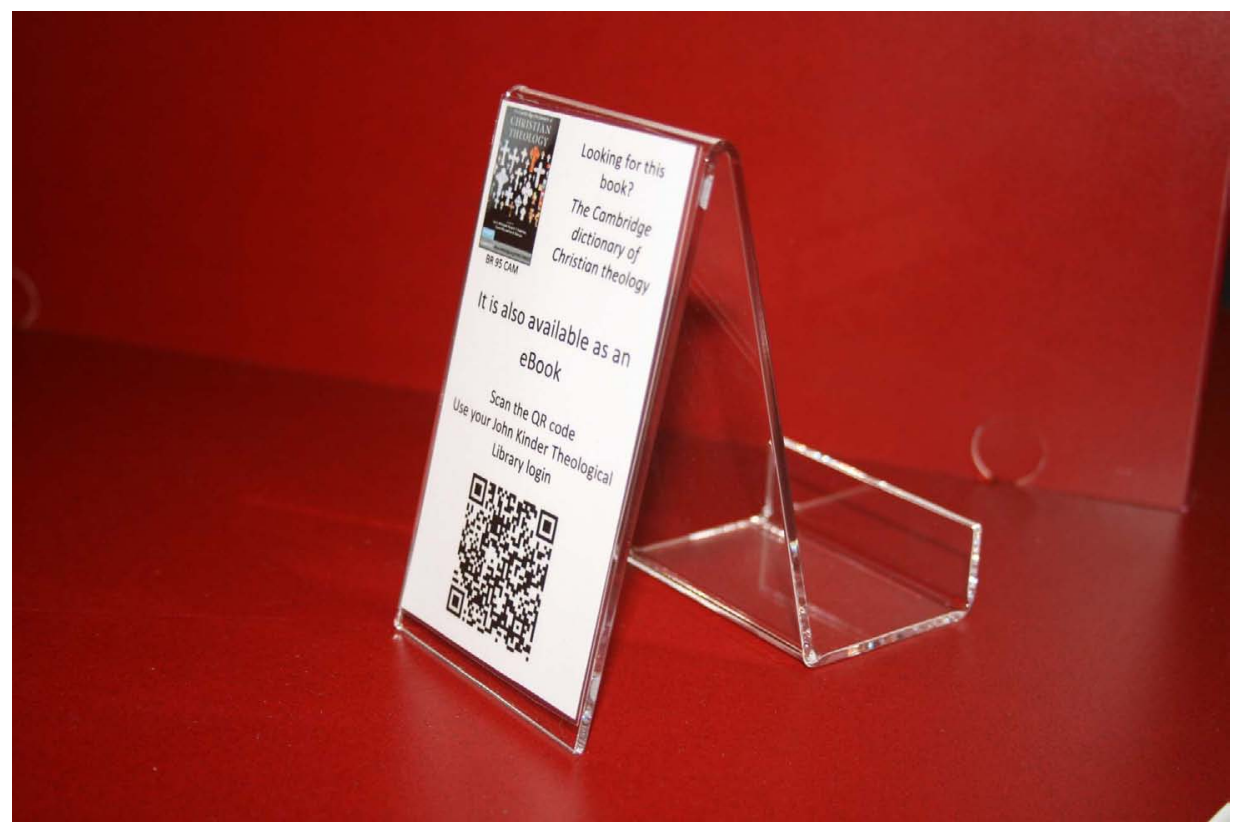




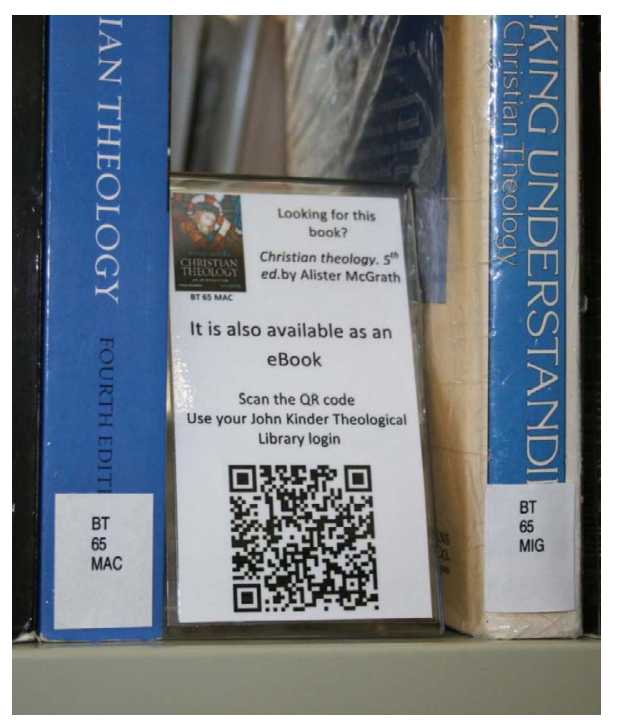

\section{Download QR code scanner}

Available free from App Store or Google Play

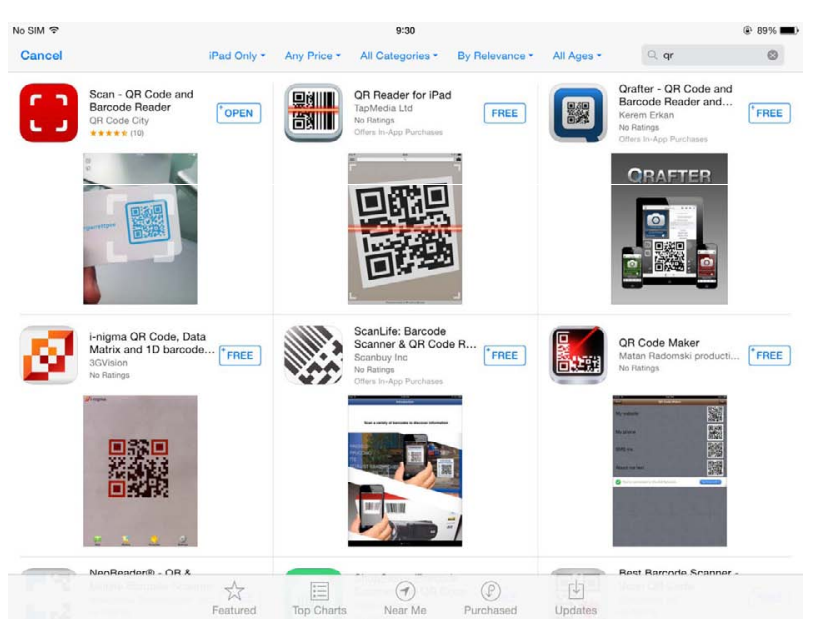




\section{Scan, authenticate, access}

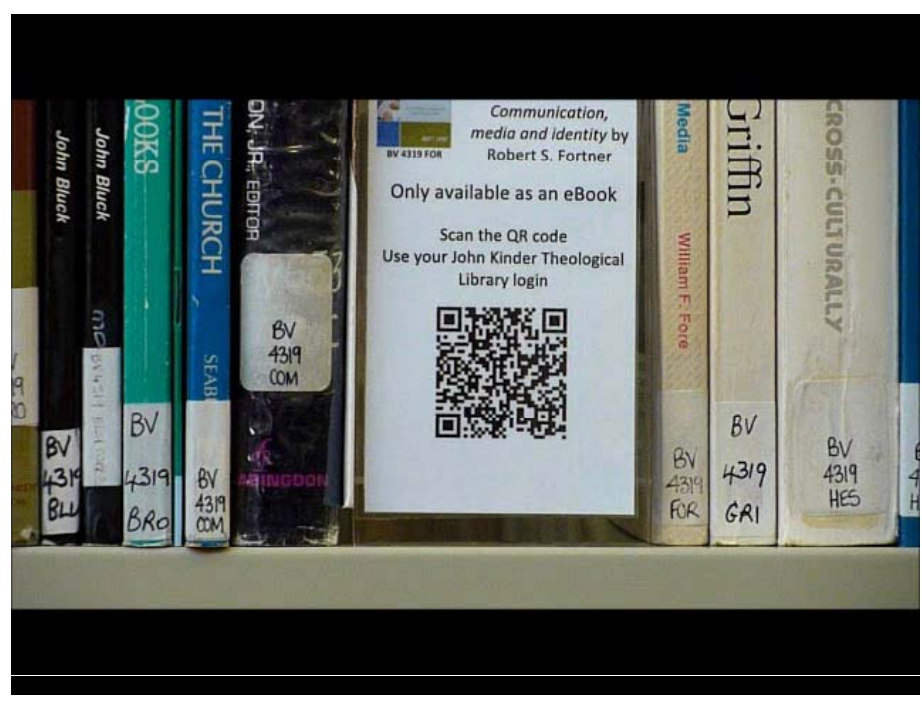

\section{Have a go}

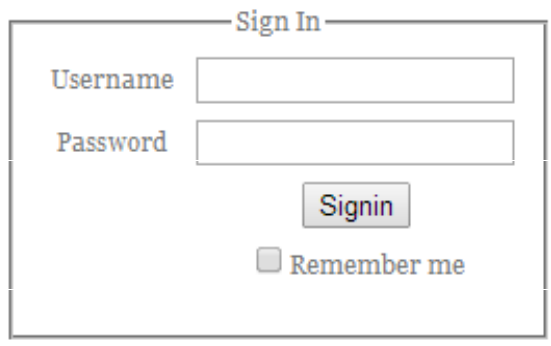

\section{Username B06290642 \\ Password 0642}




\section{Publicity}

- Colourful easels in the shelves

- Practical demonstration during library orientation

- Facebook post

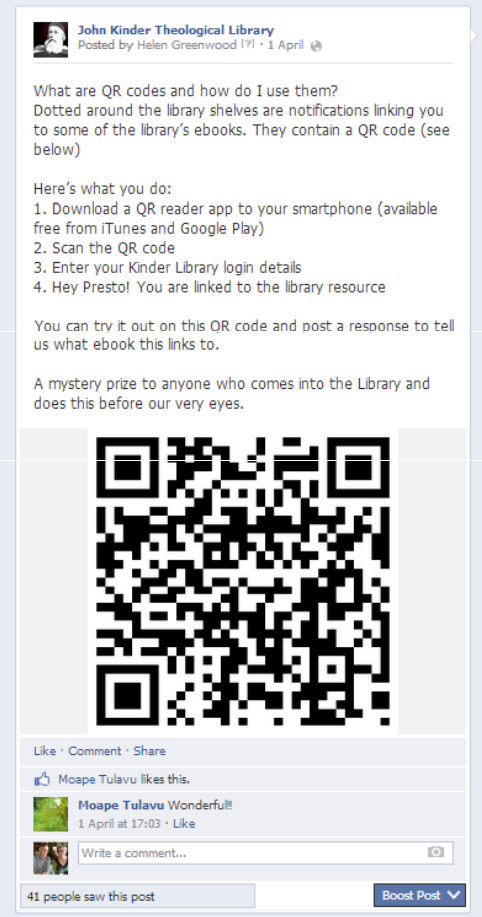




\section{Uptake}

- Ultimately, we have no way of knowing how many people are using QR codes

- One documented example when library user whipped out their smartphone in front of a library staff member and followed the process through 